EGU2020-2325, updated on 20 May 2020

https://doi.org/10.5194/egusphere-egu2020-2325

EGU General Assembly 2020

(c) Author(s) 2020. This work is distributed under

the Creative Commons Attribution 4.0 License.

\title{
Structure of the south-central Taiwan fold-and-thrust belt
}

\author{
Dennis Brown ${ }^{1,2}$, Joaquina Alvarez-Marron ${ }^{1}$, Hao Kuo-Chen ${ }^{2}$, Yih-Min $\mathrm{Wu}^{3}$, Giovanni Camanni ${ }^{4}$, and \\ Cristina Biete ${ }^{1}$ \\ ${ }^{1}$ ICTJA, CSIC, Barcelona, Spain (dbrown@ictja.csic.es, jalvarez@ictja.csic.es) \\ ${ }^{2}$ Department of Earth Sciences, National Central University, Zhongli, Taiwan (kuochen@g.ncu.edu.tw) \\ ${ }^{3}$ Department of Geosciences, National Taiwan University, Taipei, Taiwan (drymwu@g.ntu.edu.tw) \\ ${ }^{4}$ Department of Earth Sciences, University of Naples Federico II, Naples, Italy (giovanni.camanni@unina.it)
}

Studies of mountain belts worldwide have shown that the structural, mechanical, and kinematic evolution of their foreland fold-and-thrust belts are strongly influenced by the structure of the continental margins that are involved in the deformation. The area on and around the island of Taiwan provides an unparalleled opportunity to investigate this because the entire profile of the SE margin of the Eurasian plate, from the shelf in the north to the slope and continent-ocean transition in the south and the offshore, is currently involved in a collision with the Luzon arc on the Philippine Sea plate. Taiwan can, then, provide key insights into how such features as rift basins on the shelf, the extensional faults that form the shelf-slope break in the basement, or the structure of the extended crust and morphology of the sedimentary carapace of the slope can be directly reflected in the structural architecture, the location and pattern of seismicity, topography, and the contemporaneous stress and strain fields of a fold-and-thrust belt. For example, eastnortheast striking faults that have been mapped on the necking zone of the Eurasian margin can be traced into the island of Taiwan where they are causing important along-strike changes in various aspects of the structural, mechanical, kinematic, and morphological behavior of the foldand-thrust belt. In particular, across the upper part of the necking zone there is an abrupt northsouth change in structure, an increase in the amount of seismicity, an increase in topography, a rotation of the direction of maximum compressive horizontal stress, of the GPS displacement vectors, the compressional strain rate, and the maximum shear strain rate. These changes are interpreted to be caused by east-northeast striking, dextral strike-slip faulting in the basement that is taking place as a result of the reactivation of pre-existing faults along the upper part of the necking zone. The abrupt southeastward increase in topography across the upper part of the necking zone is the surface expression of the basal thrust of the fold-and-thrust belt ramping down into the basement, with maximum elevations reached in the basement-involved thrust sheets, suggesting a causal link between basement involvement in the thrusting and high topography. On the shelf, the roughly northeast-oriented Hsuehshan Trough is inverting along almost north-south striking basin bounding faults that penetrate into the middle crust and have well-clustered, deep seismicity. There are no substantial differences in the contemporaneous stress and strain field. There is, however, a clear relationship between basement involvement in the thrusting and the development of high topography in the Hsuehshan Range. Only the upper 
part of the slope is involved in the fold-and-thrust belt in southernmost Taiwan. In this area, there is a reduction of the amount of seismicity and lower topography. The largest part of the corresponding thrust wedge developed in the lower slope is offshore. This work is funded by the Spanish Ministerio de Ciencia, Innovación y Universidades grant PGC2018-094227-B-100. 